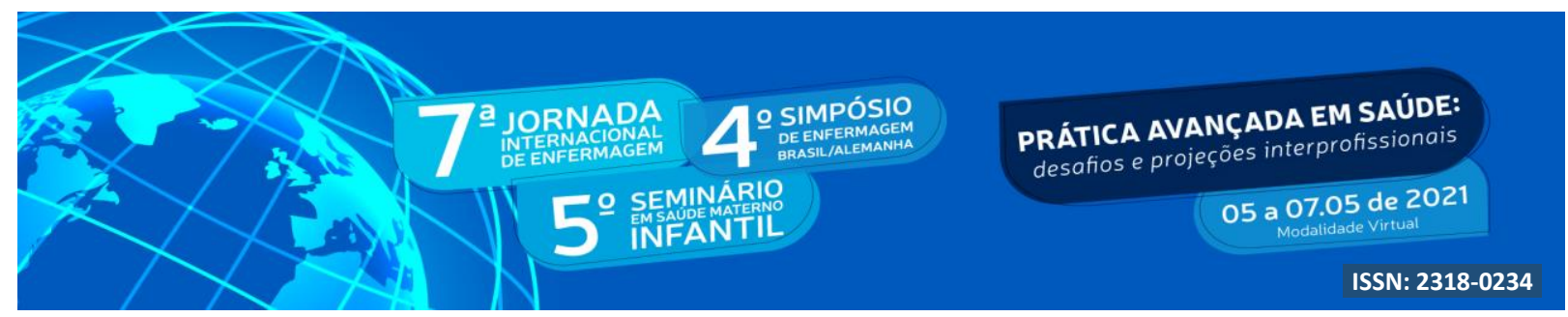

DOI: http://doi.org/10.48195/jie2021-144

\title{
ARTE COMO TECNOLOGIA DE HUMANIZAÇÃO NO PARTO E NASCIMENTO ${ }^{1}$
}

\section{Maria Luisa Suárez Gutiérrez Cella ${ }^{2}$; Marcli Firpo Bitencourt ${ }^{3}$; Nathalia Adames ${ }^{4}$; Claudia Zamberlan ${ }^{5}$; Dirce Stein Backes ${ }^{6}$}

\begin{abstract}
RESUMO
Na maternidade há um espaço para favorecer o parto e o vínculo mãe-bebe, onde a humanização é fundamental.Este trabalho busca apresentar a importância das práticas humanizadoras através da arte terapia.Objetivou-se criar uma tecnica lúdica para a humanização do parto e nascimento que envolvesse crianças e familias,como prática de uma disciplina de Mestrado.Trata-se de um relato de experiência de mestrandas,a partir da confeccção de aparatos decorativos por crianças de seis a oito anos, que frequentavam o ensino fundamental $\mathrm{e}$ as consequencias destes atos no reforço da humanização de um hospital do interior do Rio Grande do Sul.Os resultados apontaram para a satisfação das parturientes quanto a arte utilizada, a estética dos espaços e o tratamento acolhedor da equipe hospitalar.Conclui-se então que um ambiente esteticamente harmonizado e humanizado favorece o bem estar, mantém a saúde mental das mães e da equipe hospitalar merecendo uma avaliação constante desta prática.
\end{abstract}

Palavras-chave: Humanização; Maternidade; Crianças

\section{ABSTRACT}

In maternity there is a space to favor childbirth and the mother-baby bond, where humanization is fundamental. This work seeks to present the importance of humanizing practices through art therapy. The objective was to create a playful technique for the humanization of childbirth and birth that involved children and families, as a practice of a Master's course, from the making of decorative apparatuses by children from six to eight years old, who attended elementary school and the consequences of these acts in reinforcing the humanization of a hospital in the interior of Rio Grande do Sul. The results pointed to the parturients' satisfaction regarding the art used, the aesthetics of the spaces and the welcoming treatment of the hospital team.It is concluded, then, that an aesthetically harmonized and humanized environment favors well-being, maintains the mental health of mothers and hospital staff, deserving a constant evaluation of this practice.

Key Words: Humanization; Maternity; Children

\footnotetext{
${ }^{1}$ Trabalho de extensão - Universidade Franciscana

${ }^{2}$ Doutoranda em Nanociências - UFN. malu_suarez@hotmail.com

${ }^{3}$ Mestre em Saúde Materno Infantil - UFN. marclib@bol.com.br

${ }^{4}$ Mestre em Saúde Materno Infantil - UFN.natiadames@gmail.com

${ }^{5}$ Professora do Curso de Mestrado Profissional em Saúde Materno Infantil - UFN. claudiaz@ufn.edu.br

${ }^{6}$ Orientadora. Professora do Curso de Mestrado Profissional em Saúde Materno Infantil - UFN. backesdirce@ufn.edu.br 


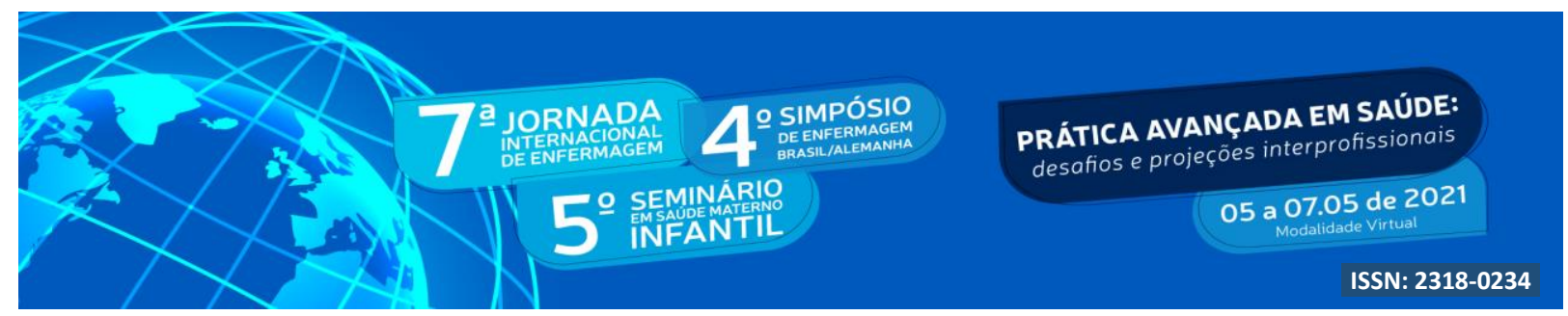

\section{INTRODUÇÃ̃O}

A prática humanizada dentro das maternidades deve ser sempre o foco dos profissionais que estão inseridos neste ambiente em contato com as gestantes e com o familiar acompanhante, pois a percepção do que o outro requer é uma atitude profundamente humana (BACKES, LUNARDI e LUNARDI FILHO, 2006, p.133). O ambiente hospitalar por si só causa determinados sentimentos nas pessoas que transitam por esse espaço dentre estes, angústia e expectativas. Ao longo do tempo buscou-se melhorar essa realidade transformando estes locais em espaços de acolhimento e produção de saúde, principalmente em relação a gestação e suas nuances. O Programa Nacional Humanização da Assistência Hospitalar (PNHAH) foi idealizado para possibilitar estratégias que viabilizassem a melhor interação entre as pessoas quais sejam profissionais da saúde e usuários, além do hospital com a comunidade, tendo em vista um objetivo que se configura como o funcionamento do Sistema de Saúde junto com a Política Nacional de Humanização (PNH), que apresenta as orientações para que ocorra a implementação de um processo de humanização nos serviços de saúde do Sistema Único de Saúde (SUS) no Brasil (BRASIL, 2002). A Política Nacional de Humanização (Humaniza SUS), que tem a humanização como eixo norteador, foi criada para melhorar as relações entre os diferentes profissionais da saúde e destes com a clientela devendo ser aplicada em todas as práticas de Atenção e Gestão, em todas as instâncias do SUS. Essa Política defende a humanização da assistência, oferecendo qualidade no atendimento, articulando os avanços tecnológicos com acolhimento, melhorando os ambientes de cuidado e das condições de trabalho dos profissionais (BRASIL, 2004, p.6). Refletindo sobre o Programa Nacional de Humanização da Assistência Hospitalar, BETINELLI, WASKIEVICZ e ERDMANN (2003, p. 238) destacam o ato de humanizar como uma estratégia para melhorar a qualidade de vida. Considera-se uma atitude positiva com valor ético e estético que fortalece os laços e qualidades humanas. Ambientes decorados e coloridos produzem sensação de bem estar e acolhimento. Na situação vulnerável que se encontram os pacientes frente à hospitalização e em especial a gestante suscetível a muitas emoções, o fato 


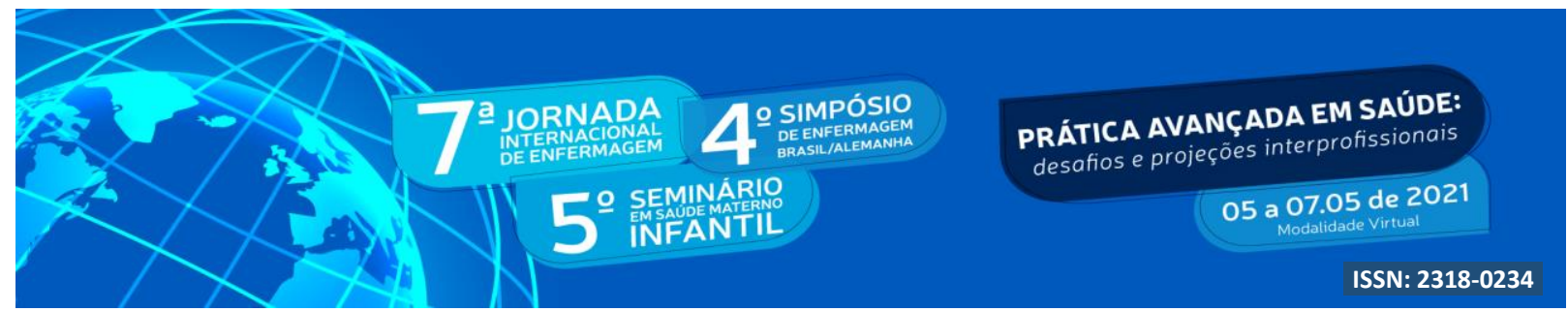

de ser recebida em um local decorado para deixá-la feliz e tranquila pode ajudar significativamente no momento do parto. Para Coqueiro; Vieira; Freitas (2010) a Arte terapia é um dispositivo terapêutico que absorve saberes transdisciplinares, visando processos de autoconhecimento e mudanças de comportamento, sendo um processo predominantemente não verbal, por meio das artes, que acolhe o ser humano com toda sua complexidade e dinamicidade.

A Arte terapia por meio das cores causam efeitos positivos nas pessoas. Evidências científicas sugerem que a luz de diversas cores é percebida pelo olhar e afeta diretamente o centro das emoções. O modo como cada um é impactado pode estar vinculado à personalidade e às condições de vida ou de desejos e a processos mentais mais íntimos e profundos, provavelmente inconscientes (AMBROSE e HARRIS, 2010).

O período gestacional é envolto por expectativas em relação à vida que se desenvolve e ao momento do parto. Durante nove meses a mulher carregou em seu ventre o bebê. Desde a descoberta até o momento do parto, muitas surpresas, emoções, alegrias, ansiedades, angústias estiveram presentes, cria-se então em sua mente uma forma representativa de um bebê imaginário. As representações maternas têm grande importância no estabelecimento das relações posteriores entre mãe e filho. Por meio do imaginário em relação ao filho a mãe terá, progressivamente, condições de estabelecer contato com o bebê da realidade que pode atender ou não suas expectativas, mas que com essa vivência a gestante começa a experiência da maternidade e se pautará para interpretar as necessidades e sinais enunciados por seu bebê real (CARON, 2000).

Essa realidade ocorre com todas as gestantes e, assim, a dúvida e o medo acompanham-na ao chegar à maternidade. A partir do momento que elas encontram um cenário acolhedor, preparado para seu bem-estar, a ansiedade diminui, acarretando em um parto satisfatório propiciando um nascimento de maior qualidade e uma aceitação propicia a este novo momento que vive, o da maternidade.

Quando se refere ao cenário, entende-se, como o lugar onde ocorre a ação, espaço real onde a história se passa, mais especificamente neste estudo, o lugar onde as gestantes são 


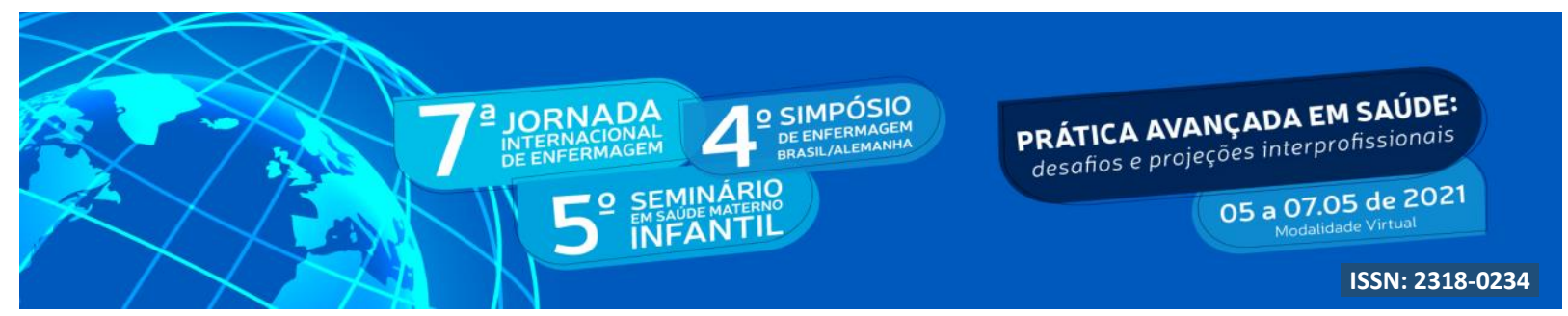

recebidas para a realização do parto e acontecem os nascimentos: o ambiente hospitalar.

Quando se aborda a ambiência, se pensa em humanização por meio do equilíbrio de elementos que compõem os espaços, considerando fatores que permitam o protagonismo e a participação das pessoas envolvidas. Já, o ambiente é o conjunto de condições materiais, culturais, psicológicas e morais que envolvem uma ou mais pessoas (BESTETTI, 2014). Portanto, por ambiente entende-se como tudo que cerca ou envolve os indivíduos que estão naquele cenário, incluindo tanto sua parte física, como a sua parte psicossocial.

Nesse enfoque, é necessário analisar as condições ambientais que serão vivenciadas pelos usuários desse serviço, em especial, a gestante, já que a mesma é capaz de interagir com o ambiente por meio dos sentidos. Essa percepção sensorial é particular de cada indivíduo considerando a experiência de vida das pessoas, (BOTTON, 2007). Esse fato revela a capacidade de sentir a quantidade de emoção recebida em sua vida, e o quanto essas emoções geram satisfação nos mesmos.

\section{OBJETIVO}

Criar uma tecnologia lúdica para a humanização do parto e nascimento por meio da arte terapia, a fim de favorecer melhor ambiência.

\section{METODOLOGIA}

Trata-se de um relato de experiência, desenvolvido na disciplina de Tecnologia e Empreendedorismo em Enfermagem/Saúde do Curso de Mestrado Profissional em Saúde Materno Infantil. Assim, se busca apresentar uma reflexão sobre a importância da ambiência e os potenciais da arte terapia no processo da atenção humanizada e do trabalho em equipe de uma maternidade de um Hospital Público da cidade de Santa Maria/RS. A unidade foi decorada por quadros e figuras ilustrativas referentes à maternidade, pintados por crianças de 


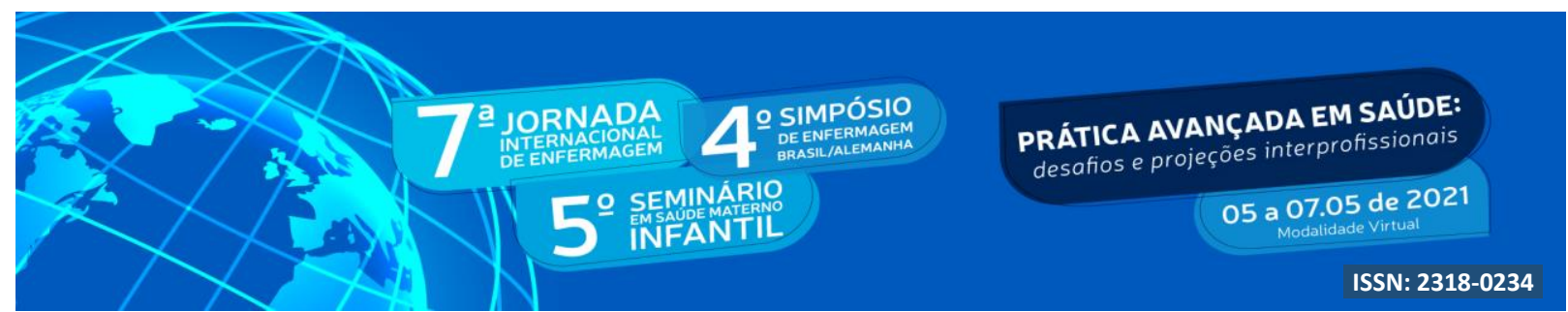

6 a 8 anos de duas escolas de ensino fundamental e por filhos dos funcionários da maternidade. Foram confeccionados também moldes em gesso das barrigas de gestantes voluntárias e oferecidas lembrancinhas de carimbos das placentas para as puérperas com dados dos seus bebês e com assinaturas dos que participaram do parto. Ademais, foram realizadas reuniões prévias na maternidade com a equipe de saúde e com as escolas participantes para discutir assuntos referentes à confecção dos materiais e locais de colocação dos trabalhos.

\section{RESULTADOS E DISCUSSÃO}

O Ambiente hospitalar é um local bastante sério, até porque acolhe inúmeras pessoas nas mais diferentes situações. $\mathrm{O}$ acolhimento nestes setores da saúde muitas vezes devido a suas limitações como alta demanda de pacientes e de falta de funcionários, leva a automatização do atendimento e de condutas que não são compatíveis com a lógica do atendimento defendida pela Política Nacional de Humanização.

O ambiente torna-se humanizado porque tem alguma capacidade para interagir de maneira benéfica, agradável com o seu usuário (CIACO, 2010). Assim ressaltar a humanização e brindá-las com práticas educativas favorece o bem estar da equipe, da mãe e da família da mesma.

Assim a dor da gestante em trabalho de parto e a sua preocupação pelo nascituro ,o que gera na maioria das vezes situações de vulnerabilidade e ansiedade por parte dos familiares e das pacientes que buscam assistência, poderá ser minimizado favorecendo a saúde mental de toda família, em especial da mãe(STEEEN,2021)

A arte torna-se uma importante ferramenta como estratégia para promover mudanças qualitativas no atendimento ao parto e nascimento, restaurando o significado do acolhimento. Atuando também como via de conhecimento, apresentando outros modos de enxergar o ambiente hospitalar; elaborando memórias, enriquecendo a compreensão, gerando sentimentos e sensações que podem resultar na produção de relações mais éticas e comprometidas pela equipe de trabalho e um atendimento mais humanizado à gestante. 


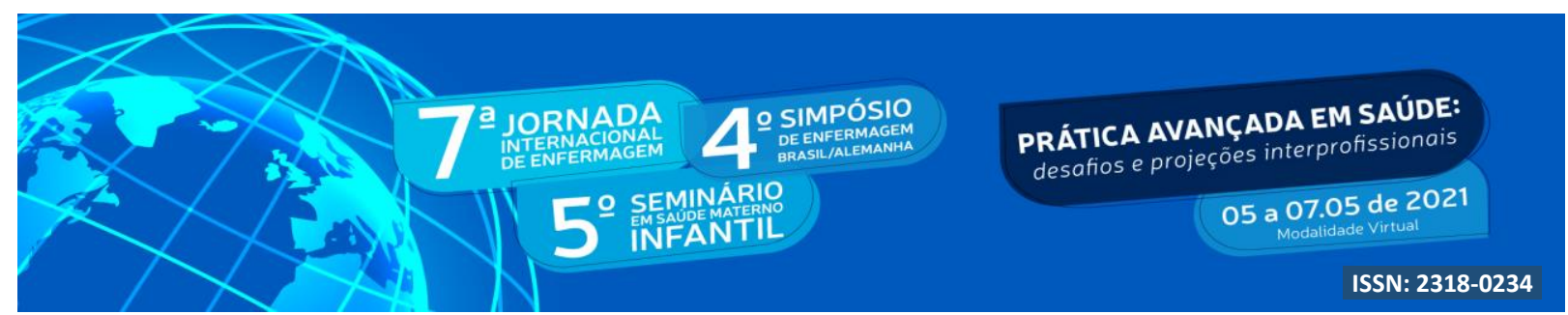

\section{CONCLUSÃO}

Pretende-se que a transformação simbólica destes espaços mediante a arte terapia, construa e transforme uma rotina hospitalar mecanizada em um modelo de atendimento mais humanizado, onde a dignidade humana e o respeito pelos funcionários e usuários sejam a base transformadora para redirecionar as boas práticas.O trabalho realizado mostrou bons indicativos diante deste premissa, mas requer uma avaliação constante da satisfação dos usuários, a fim de que se possa romover mais ações educativas dentro das maternidades.

\section{REFERÊNCIAS}

AMBROSE, G; HARRIS, P. Cor. Porto Alegre/RS, Editora Bookman Companhia, 2010.

BACKES, D.S.; LUNARDI V.L.; LUNARDI FILHO W.D. A humanização hospitalar como expressão da ética. Rev. Latino - Am. Enfermagem, Ribeirão Preto, v. 14, n. 1, p.132 - 5 jan/fev 2006.

BESTETTI, M.L.T; Ambiência: espaço físico e comportamento. Rev.Bras. de Geriatria e Gerontologia. 2014.

BETTINELLI, L.A, WASKIEVICZ, J; ERDMANN, A.L. Humanização do cuidado no ambiente hospitalar. Mundo Saúde. 2003 Abr-Jun; 27 (2): 231-9.

BOTTON,A. A Arquitetura da Felicidade. Rio de Janeiro: Rocco; 2007.

BRASIL. Manual do Programa Nacional Humanização da Assistência Hospitalar (PNHAH). Brasília: Ministérios da Saúde, 2000.

BRASIL. Secretaria - Executiva. Núcleo Técnico da Política Nacional de Humanização. Humaniza SUS: Política Nacional de Humanização: a humanização como eixo norteador das práticas de atenção e gestão em todas as instâncias do SUS. Brasília: Ministério da Saúde, 2004. 


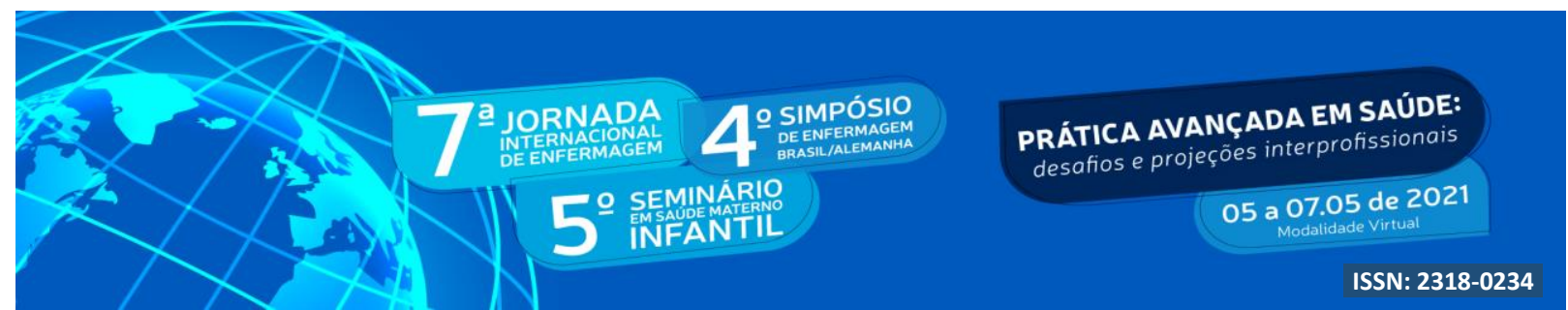

BRASIL. O que é o SUS. Disponível em: <www.portalms.saude.gov/sistema de saúde> Acesso em: 12 de maio de 2019.

CARON,N.A; organizadora. A relação pais-bebê: da observação à clínica. São Paulo: Casa do Psicólogo; 2000.

CIACO, J.R.A.S; A arquitetura no processo de humanização dos ambientes hospitalares (dissertação). São Carlos (SP): Escola de Engenharia de São Carlos; 2010.

COQUEIRO, N. F; VIEIRA, F. R. R; FREITAS, M. M. C. Arte terapia como dispositivo terapêutico em saúde mental. Acta paulista de enfermagem, São Paulo, v. 23, n. 6, 2010.

STEEN,M; FRANCISCO, A.A. Bem-estar e saúde mental materna. Acta paul. enferm. , São Paulo, v. 32, n. 4, pág. III-IVI, agosto de 2019. Disponível em $<$ http://www.scielo.br/scielo.php?script=sci_arttext\&pid=S0103-

21002019000400001\&lng=en\&nrm=iso>. acesso em 31 de março de 2021. Epub em 12 de agosto de 2019. https://doi.org/10.1590/1982-0194201900049 . 